\title{
WATERiD's Novel Methodology for Condition Assessment Cost Data Collection and Visualization
}

\author{
Stephen M. Welling and Sunil K. Sinha \\ Department of Civil and Environmental Engineering, Virginia Tech, Blacksburg 24061, USA
}

\begin{abstract}
A profound understanding of the costs to perform condition assessment on buried drinking water pipeline infrastructure is required for enhanced asset management. Toward this end, an automated and uniform method of collecting cost data can provide water utilities a means for viewing, understanding, interpreting and visualizing complex geographically referenced cost information to reveal data relationships, patterns and trends. However, there has been no standard data model that allows automated data collection and interoperability across platforms. The primary objective of this research is to develop a standard cost data model for drinking water pipeline condition assessment projects and to conflate disparate datasets from differing utilities. The capabilities of this model will be further demonstrated through performing trend analyses. Field mapping files will be generated from the standard data model and demonstrated in an interactive web map created using Google Maps API (application programming interface) for JavaScript that allows the user to toggle project examples and to perform regional comparisons. The aggregation of standardized data and further use in mapping applications will help in providing timely access to condition assessment cost information and resources that will lead to enhanced asset management and resource allocation for drinking water utilities.
\end{abstract}

Key words: Drinking water pipeline, condition assessment, water pipeline cost data.

\section{Introduction}

The buried drinking water pipeline infrastructure in the US is continuously deteriorating, with the potential to have increasingly harmful social and environmental consequences. The ASCE (American Society of Civil Engineers) gave the nation's water infrastructure a " $D$ " rating in its 2013 report card, with over 700 cities and towns being adversely affected by combined sewer systems prone to overflow events [1]. \$384 billion dollars is needed to rehabilitate or replace drinking water pipelines that have reached or are beyond their useful service lives to maintain current performance over the next 20 years [2, 3]. The USEPA (United States Environmental Protection Agency) has sought to remedy these problems by directing utilities to implement advanced methods for the operations and management of public drinking water and drinking water systems. Drinking water utilities must improve

Corresponding author: Stephen M. Welling, professional engineer, research field: water pipe asset management. E-mail: Stevo82@vt.edu. the efficiency with which their systems are operated and maintained, and particularly seek to understand the risk of failure of their buried pipelines. Utility managers are actively working to develop asset management plans that incorporate CA (condition assessment) practices to fully understand the nature of their buried pipeline assets. The management of drinking water infrastructure is extremely important in the preservation of the environment, public health and the economy. CA is one of the core components of an asset management program, providing critical information needed to assess the remaining useful life and long-term performance of a piping system [4] and therefore help prioritize pipeline asset management activities.

\subsection{Background}

Cost data management is key to any infrastructure management system, built on the availability of an accurate inventory of the existing infrastructure [5]. Yet, data can exist in many forms and homogeneity can 
only be found through advanced means of computing [4]. Greater efforts in cost data management are required to aid decision makers in their critical management decisions with respect to operations, maintenance and capital planning.

Prior endeavors have looked at several facets of cost estimation. One entailed cost estimation modeling for water pipe projects, but only looked at the direct costs of the work [6]. The true costs of the project can only be seen when considering initiatory costs such as design and planning, decommissioning, and all other related costs paid out by the utility. Another study shows only the direct unit costs of some trenchless methods [7] and another only considers a few cost drivers [8]. USEPA supported previous research that determined that adequate amounts of comprehensive, pipeline CA costs are difficult to capture from the industry. Further, they determined that a centralized cost database is necessary for utilities to better share, analyze and utilize cost data in decision making [3]. Also, researchers showed that the use of a web-accessible tool was useful in helping utilities in decision making for asset management $[9,10]$.

Cost data for buried drinking water pipeline infrastructure are available in inconsistent formats and are collected and stored differently, even within the same utility. Consequently, the need for a cost data standard that can homogenize and sanitize data, and further provide direct comparisons for trend and relationship analysis to drive decision making from project through managerial levels is apparent. This collection and conflation process is shown in Fig. 1. This image explains how the disparate cost data collected from multiple utilities can be collected, standardized and stored in an automated manner. Normally, these standards do not currently exist in a nationally-recognized format, hence limiting managers' ability to extract a great deal of useful information in investment decision-making.

A national and web-based interactive database for water infrastructure systems was developed in order to provide a standard platform through which institutional knowledge on the several fronts could be shared, called WATERiD (Water Infrastructure Database, www.waterid.org). The intent of this national database is to provide a "one-stop-shop" for a utility researching the costs of technologies or products to apply to a specific project or to approve for use within their municipality. WATERiD contains information on both drinking water and wastewater infrastructure networks. Information about pipeline condition assessment, pipeline renewal engineering, subsurface utility engineering for locating pipelines, management practices, models and tools, costs, benchmarking and product qualification is included. This paper focuses on the development of a methodology for collecting and standardizing the costs of condition assessment work for drinking water pipelines that was performed as part of the project.

\subsection{Objectives and Scope}

The objective of this paper is to enhance industry understanding of costs to support CA decisions for buried drinking water pipeline infrastructure by developing a framework for collecting and standardizing cost data in an automated manner. Further, it considers
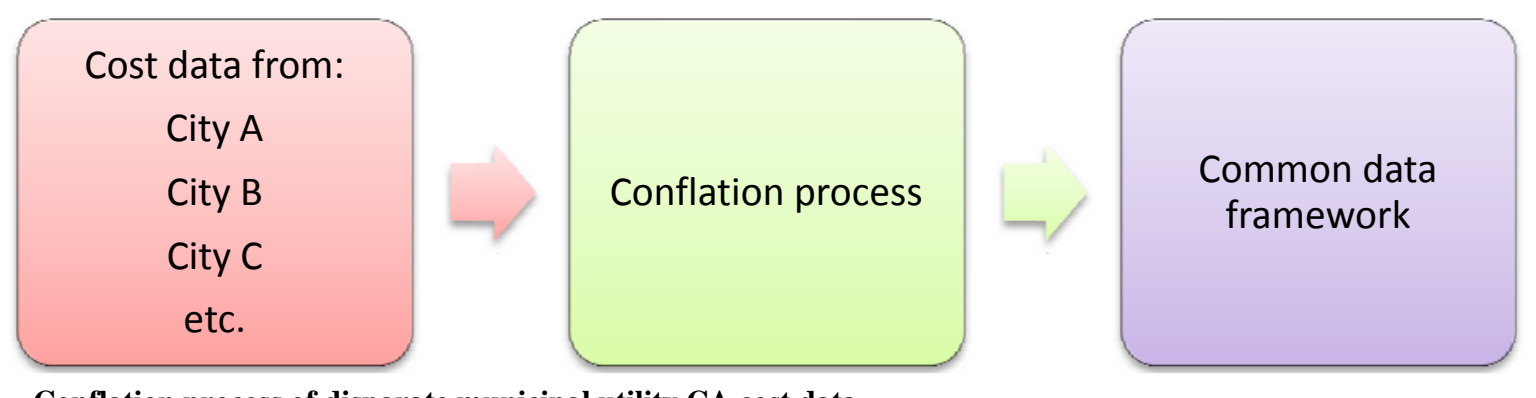

Fig. 1 Conflation process of disparate municipal utility CA cost data. 
how CA cost information, when captured in a standard data structure, can produce better statistical analyses for trends and drivers. The key objectives of the paper are as follows:

(1) develop a methodology for collecting and standardizing the costs of condition assessment work for drinking water pipelines that was performed as part of the WATER $i \mathrm{D}$ project;

(2) collect data from drinking water utilities across the US and conflate it according to the standardized model;

(3) analyze the collected data to uncover apparent cost trends and drivers in direct costs for the various CA technologies surveyed, e.g., SmartBall and sonar;

(4) develop an interactive web map in WATER $i \mathrm{D}$ for users to access cost data and look for regional trends.

This endeavor included a comprehensive review of the published research on the cost of drinking water pipeline CA technologies. The research team then performed data mining through soliciting input through a standardized spreadsheet that could be placed in a utility's own FTP (file transfer protocol) site and then accessed via WATERiD's ETL (extract, transform and load) tool, as outlined in Fig. 2. This began with converting the cost data into a uniform framework and entering it into the cost database using data links between the incoming data and the new model. The homogenous data could then be inserted it into a geodatabase to drive the query tool outlined in Section 5 that allows utilities to get a snapshot of what is happening across the country regarding this type of work.

Some data would be generally missing, wherein utility personnel interviews and public utility records filled in the gaps. Additionally, an expert committee made up of utility managers and consultants provided direction as to the development and implementation of the cost data collection and management methodology. Some limitations included not being able to capture every single type of cost, making some assumptions as to the similarity of projects in grouping them together, and finally assuming that the data received through the collection and interviews were indeed accurate.

\section{Condition Assessment Technologies}

Acoustic technologies help find pipe defects by detecting vibrations and/or sound waves. Signals are

\section{Extract, transform, and l oad (ETL)}

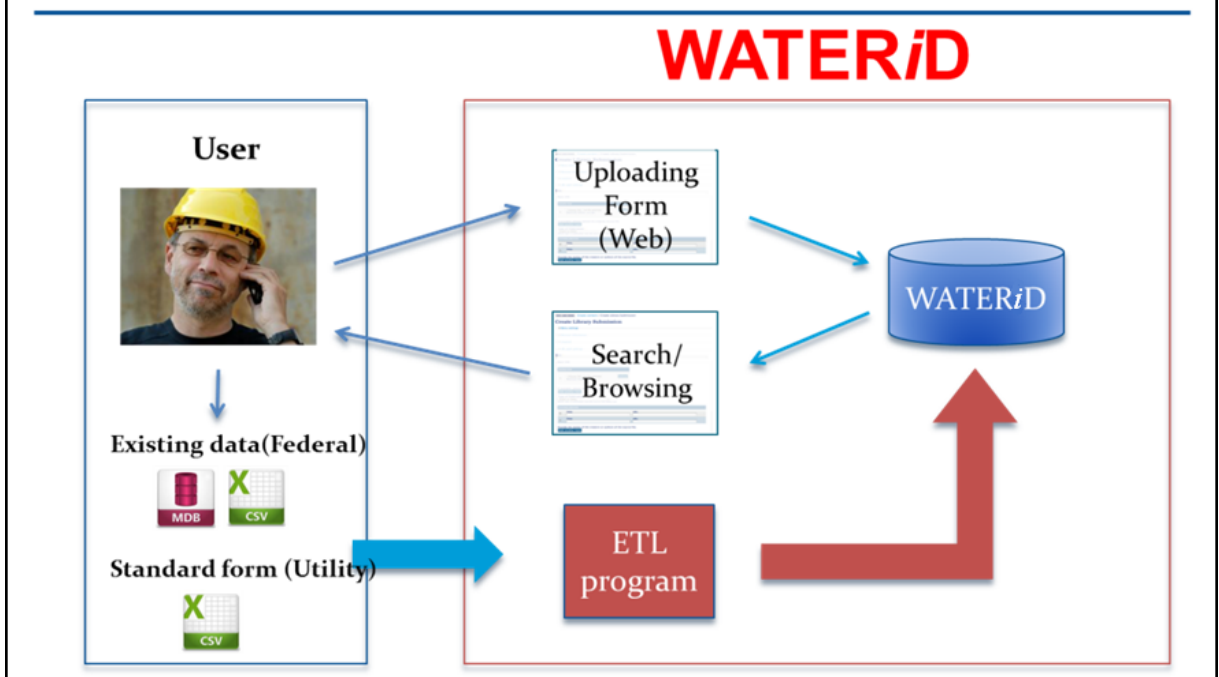

Fig. 2 ETL data collection and storage process. 
emitted by certain pipe defects and can be sensed by a variety of commercially available instruments. Acoustic technologies are used mostly for inspection of water mains, but can also be used for force mains. Some technologies can be used in gravity sewers.

Acoustic technologies can be classified into the following three categories:

- leak detectors, which detect the acoustic signals created by pipeline leaks;

- acoustic monitoring systems, used to detect breaking wires in PCCP (prestressed concrete cylinder pipe) and thus evaluate its condition;

- sonar/ultrasonic systems, which emit high frequency sound waves and measure their reflection off the pipe wall to detect pipe wall deflections, corrosion, pits, voids, cracks and debris.

Inline acoustic leak detection is a type of non-destructive technology in which acoustic sensors are passed along the pipeline while the pipeline is in service. These sensors detect noise emanated by leakages in the pressurized pipes. The amplitude and frequency of noise depend on variety of factors such as pipe material and internal pressure. The most widely used leak detection system is the leak-noise correlator (with which leak noise signals travel to multiple sensors and the origin of the leak noise is determined by the time the noise takes to travel to those sensors). However, at any significant distance from the leak points, the leak noise signal is swamped by background noise. This problem led to the invention of inline acoustic leak detection equipment. These technologies can either be tethered or free-swimming. The two commercially available leak monitoring equipment options are Sahara ${ }^{\circledR}$ and SmartBall ${ }^{\circledR}$ both by Pure Technologies, Calgary, Alberta, Canada. Sahara is a tethered system in which an acoustic sensor mounted on an umbilical cord is inserted into the pipe to be inspected for leaks. The length of pipe that can be assessed is approximately 3 miles. The SmartBall is a free-swimming system, in which an acoustic sensor in a floatable ball is inserted in the pipe. The length of pipe that can be assessed by the SmartBall depends on the flow velocity, as the tool is rated $13 \mathrm{~h}$ of data collection. This equates to a distance of about 12 miles under normal conditions.

\subsection{Standard Data Structure}

During the course of this research project, much time was taken to gather information from literature and directly from utilities in order to gather and understand the current practices related to condition assessment projects for drinking water pipelines. Additional information would be useful to better understand and improve the operation of drinking water pipelines on different management levels. Based on the work completed on WATERiD, it became apparent that, in order to more efficiently gather data about drinking water pipeline condition assessment projects, it would be beneficial to create a standard data structure. This section proposes a standard data structure for the collection of project cost information on condition assessment technologies for drinking water pipelines. The standard data structure was written with the intention of making the structure capable of being aggregated and input for analysis at different management levels for different output needs.

\subsection{Proposed Cost Data Structure}

The parameters to be collected, along with a description of the data, are described in detail below. Data will be collected through the internet and therefore the fields for collecting the parameters described may have specific formats or characteristics. A summary of the parameters included in the standard data structure is shown in Table 1. More detailed descriptions of each of the fields created to collect the parameter information are as follows.

\section{Methodology for Piloting the Standard Data Collection Methodology}

Utilities were solicited in the gathering of drinking water pipeline CA project costs. Cost practices were 
Table 1 Summary of parameters included in proposed standard data structure.

\begin{tabular}{|c|c|c|c|}
\hline No. & Field name & Parameter description & $\begin{array}{l}\text { Format of } \\
\text { field }\end{array}$ \\
\hline 1 & Utility name & Name of the reporting utility & Text \\
\hline 2 & Utility location & State in which the utility is located & List \\
\hline 3 & Utility population served & The population served by the utility & Integer \\
\hline 4 & Project location description & Description of the exact project location & Text \\
\hline 5 & Project start date & Start date of the project condition assessment & Date \\
\hline 6 & Project end date & End date of the project condition assessment project & Date \\
\hline 7 & Hours & Total time of the actual condition assessment & Numeric \\
\hline 8 & Rate & Rate at which the condition assessment work was performed & Numeric \\
\hline 9 & Total project cost & Total cost of the condition assessment project & Numeric \\
\hline 10 & Pipeline material & Material(s) of the pipeline that was assessed during the project & Text \\
\hline 11 & ID & Internal diameter(s) of the pipeline assessed in $\mathrm{cm}$ & Numeric \\
\hline 12 & Pipeline installation year & Year the pipeline was initially installed & Date \\
\hline 13 & Pipeline length & Length of the pipeline that was assessed in metres & Numeric \\
\hline 14 & Pipeline type & $\begin{array}{l}\text { Type of pipeline assessed as related to the flow handled by the pipeline, e.g., } \\
\text { force main, lateral, etc. }\end{array}$ & List \\
\hline 15 & Consultant & $\begin{array}{l}\text { Name of the consultant hired to work on the condition assessment project, if } \\
\text { applicable }\end{array}$ & Text \\
\hline 16 & Contractor & $\begin{array}{l}\text { Name of the contractor hired to carry out the condition assessment work, if } \\
\text { applicable }\end{array}$ & Text \\
\hline 17 & Technology vendor & Name of the condition assessment technology vendor that was used, if applicable & Text \\
\hline 18 & Technology used & $\begin{array}{l}\text { The main technology category under which the condition assessment technology } \\
\text { used for the project falls, based upon the technology's mode of operation }\end{array}$ & List \\
\hline 19 & $\begin{array}{l}\text { Technology used } \\
\text { (subcategory) }\end{array}$ & $\begin{array}{l}\text { Depending upon the selection made for "technology used", the specific } \\
\text { technology that was used }\end{array}$ & List \\
\hline 20 & Product used & The brand name of the condition assessment product used & Text \\
\hline 21 & Defects found & The type(s) of defects found by carrying out the condition assessment project & Text \\
\hline 22 & $\begin{array}{l}\text { Known environmental } \\
\text { characteristics }\end{array}$ & $\begin{array}{l}\text { Any pipeline environmental characteristics, known before the completion of the } \\
\text { condition assessment project, internal or external to the pipeline, including } \\
\text { depth, soil condition, proximity of other utilities, etc. }\end{array}$ & Text \\
\hline 23 & Success of project & $\begin{array}{l}\text { The rating of success of the project regarding the attainment of pipeline } \\
\text { condition information }\end{array}$ & List \\
\hline 24 & Comments & $\begin{array}{l}\text { Additional comments about the success of the project, information about } \\
\text { obstacles encountered or other relevant information }\end{array}$ & Text \\
\hline
\end{tabular}

sought out from each of the 10 EPA (Environmental Protection Agency) regions, taking into account a variation in utility size. The strategy for gathering data for this research involved the following actions:

- telephone surveys of various drinking water utilities to better understand their current practices and identifying the gaps in industry knowledge;

- selecting US geographical regions not covered in previous data gathering projects;

- investigating the utility's current practice with an interview in order to fill the gap in current practices followed by drinking water utilities;

- contacting drinking water utilities to meet with key individuals and obtain more specific cost data and contextual information;

- data gathering to bridge the gap in information that exists in the industry as to exactly how utilities are locating, assessing and renewing their systems and the associated costs.

\section{Data Analysis and Results}

Standard data spreadsheets were emailed to several utilities participating in the WATER $i \mathrm{D}$ project and, in regions and technologies where the results were not received in adequate number, phone calls and internet data mining were performed. In all, data were gathered from 17 utilities for a total of 36 cost cases. The utility personnel then entered the cost data into the 
spreadsheet and some were placed on the utility’s FTP site and the ETL tool automatically pulled the information into the database. Others were emailed directly back to the research team. Interviews were performed with various utilities and internal documents gathered to gain the desired information on technology cost and how utilities were justifying their respective CA programs.

\subsection{Case Study: The Sewerage and Water Board of New} Orleans

The SWBNO (Sewerage and Water Board of New Orleans) CA program is driven by the extensive damage caused to their pipelines by the flooding from Hurricane Katrina in 2005. The protocol involves the testing and evaluation of the entire water system, providing recommendations for repair work and establishing certification criteria for measuring whether performance had been fully restored. The utility performed a comparison of tools as a justification for the program, specifically SmartBall and EchologicsLeakFinder ${ }^{\circledR}$. Their analysis revealed the following results: SmartBall could only be applied to lines larger than 10 inches in diameter and therefore could only be used on $26 \%$ of the system or 416 total miles. The Echologics tool could be used on all sizes in their system and could hence be used on the majority of the system, and did not face insertion/extraction issues like the SmartBall.

SmartBall performed exceptionally well in certain circumstances:

- in locations where the risk of failure cost far outweighs the cost of the CA work;

- when mains continue for a significant distance without lateral lines or other fittings prohibitive of the work;

- if the line ends in a reservoir in case the ball is missed at the extraction point.

SmartBall and similar tools require a great deal of planning and support in preparation and coordination of the work, including:
- one to three valve crews (three persons each), varying on the amount of valves needing to be closed during the assessment. Valves must be exercised prior to the test. Internal labor rates were estimated by SWBNO at \$9,900 per line investigated;

- insertion and extraction points at each end with two isolation valves at each point of entry/exit at $\$ 5,000$ in excavation each or $\$ 10,000$ per line. Vaults are an additional $\$ 7,000$ each, based on previous work performed;

- the significant costs of the work made it cost prohibitive as a high-level "screening" tool;

- customer flows will be disrupted typically for one day;

- the utility runs the risk losing the tools, wherein in this instance two were lost in the system;

- the tool may cause water quality issues as it rolls along the bottom of the pipe and can stir up sediment.

The Echologics tool required sensors to be placed at intervals of a few hundred feet, otherwise did not cause any of the cost increases associated with the intrusive nature of SmartBall ${ }^{\mathrm{TM}}$ as listed. Costs of performing portions of the work were included in the documentation gathered. The total cost for the SmartBall was $\$ 280,700$ for 14.27 miles of main surveyed of 43- to 50-inch diameter, wherein 46 leaks were detected. The contract was for $\$ 186,000$ and the internal support costs were $\$ 94,700$. This equated to $\$ 6,102$ per leak found, or \$3.73 per LF (lineal foot). The Echologics tool surveyed 71.51 miles of from 4 inches to 24 inches in diameter and successfully located 610 leaks. The total cost of the work was $\$ 1,104,650$ which equates to $\$ 1,811$ per leak or $\$ 2.93$ per LF. SWBNO concluded that the Echologics tool was a better fit for this portion of their drinking water system due to the lower cost per foot and per leak, as well as the non-intrusive nature of the work. In all, it was determined that SWBNO has a long history of using acoustic leak detection services contractors to survey its infrastructure and provide responsive leak detection. The survey results were used to create work 
orders to repair pipes in the same way that other leaks were repaired. The leaks were not always been tracked separately from leaks discovered by other means, so historical data relative to leak detection response activities are limited. Additionally, activity involving the existing work orders was not specifically tracked. Recent CA activities have been focused towards providing data for the analysis portion of the FEMA (Federal Emergency Management Agency) funded water line replacement program. The data are then used to consolidate or sequence multiple projects under multiple programs to minimize duplication of effort and inconvenience to residents and businesses. With a great deal of work being done under a variety of programs, it becomes very challenging to assemble unit cost data.

\subsection{Case Study: Anchorage Water and Wastewater Utility}

In a similar application, the AWWU (Anchorage (Alaska) Water and Wastewater Utility) recently had Pure Technologies perform SmartBall CA on 120,000 LF of transmission water mains. The target pipeline length originally selected was $63,000 \mathrm{LF}$, though this was increased to 120,000 feet to minimize the number of modifications necessary to create insertion and extraction points, and for ease of access at existing vaults and facilities. The SmartBall acoustical work was packaged with other CA work including of BEM (Broadband Electromagnetics) and corrosion analysis at selected excavation locations. The $\mathrm{CA}$ and consulting engineering work contract totaled $\$ 1.3$ million.

\subsection{Case Study: Washington Suburban Sanitary Commission}

The WSSC (Washington Suburban Sanitary Commission) conducts a comprehensive CA program for their large diameter PCCP (prestressed concrete cylinder pipe). This plan operates on a 6-year rotation and includes the inspection of all the 48 inches and larger pipes, for a total of 77 miles. This will be completed by the end of FY (fiscal year) 2013, whereas the beginning of FY 2013 will see the start of the inspection of an additional 68 miles of 36- and 42-inch lines through robotic means. Further, the six-year inspection rotation begins again in FY 2014 with coordination amongst departments to ensure that resources are available to support the intended plan. This work will involve SmartBall leak detection wherein the leaks identified will be followed up by manned inspections to verify and eliminate them as quickly and aggressively as possible. The manned teams will enter the dewatered pipes and employ visual, sounding and sonic inspections to identify all trouble spots in the pipe. An additional measure is taken in the way of electromagnetic field testing to further determine how many wires in the pipes are broken and the current yield strength of the pipe. If a pipe is found to be near failure, it is replaced and fiber optic acoustic monitoring cables along with data acquisition computers are installed in the pipe to "listen" for further wire breaks after it is placed back into service. In total, it cost WSSC nearly $\$ 150,000$ per mile to inspect its PCCP lines, or a little over \$28/LF. Historically, the inspections have shown that only $1 \% \sim 2 \%$ of these pipes need rehabilitation. WSSC has replaced 32 feet of pipe per mile on average, while performing three repairs per mile using carbon fiber patching methods. The costs associated with the replacement and repair work are $\$ 80,000$ and $\$ 70,000$, respectively, per pipe joint (16 feet), or $\$ 5,000$ and $\$ 4,375$ per foot.

The smaller diameters in their study will be mainly inspected through robotic methods in the future. High definition cameras will record visual data while electromagnetic testing will be done to determine wire breaks. The total cost of the robotic inspections is $\$ 80,000$ per mile. Sounding and sonic methods will no longer be used, and this type of monitoring will now be performed using the fiber optic system. The current plan is to have all PCCP pipelines of 48 inches and 
larger fitted with this system by the end of FY 2013. In recent years, the system has proven itself a viable tool in mitigating catastrophic failures. The most marked event occurred near the end of June in 2010 when the system warned WSSC staff that wire breaks were occurring in a 96-inch PCCP pipeline, and they decided to take it out of service immediately. Upon excavation, it was determined that a specific section of pipe was indeed near failure. The total cost of the replacement was $\$ 500,000$, which was considered a financial win for the utility when compared to a failure in late December of 2008 of a 66 -inch PCCP pipe. The direct costs of that failure alone were $\$ 1.7$ million, while indirect costs were substantial as an enormous amount of water was lost and people nearby were placed in danger. The cost of the system is roughly $\$ 128,000$ per mile and annual monitoring costs are around $\$ 13,000$ per mile. WSSC currently feels that the system in place is effective since in practice less than $2 \%$ of all pipes need actual repair or replacement. The alternative is a comprehensive pipe replacement initiative, wherein WSSC feels that $98 \%$ of all pipes replaced still have useful remaining life. The entire system of PCCP pipes has been valued at $\$ 2$ billion, hence $\$ 1.96$ billion worth of pipe would be wasted.

\subsection{Case Study: Seattle Public Utilities}

Another case study looked at Seattle Public Utilities' contract with Hydroscope, Inc. in the CA of some of their 8-inch cast iron water pipelines. The pipes included three separate sections: two installed in the 1920 s and the other in the 1950s. The work also included a rehabilitation plan and financial analysis that would save the utility an estimated $68 \%$ over the cost of a traditional open-cut replacement, with a guarantee of an additional 15 years of service life. Wall condition descriptions were defined for consistent inspection results. The signal from the hydroscope was rated in order to give a confidence rating to the inspection results. This rating was termed the signal quality index. For each inspection, the examination date, time of day, technicians involved and weather were recorded. The target distance for inspection and the hydrant number from which the hydroscope was to be launched were also recorded. For each length of pipe, graphs showing the results were provided. These graphs provided information on both general corrosion and the deepest pitting areas.

A hydroscope reliability analysis $\left(\mathrm{HYREL}^{\circ}\right)$ model was performed to produce a cost-effective alternative to full replacement. All recommendations were prescribed for completion within one to five years and the estimated costs for performing each restoration measure were provided. Each cost estimate was believed to be sufficient to include the costs of any warranted reconnection and/or relocation of services. Notes on specifications for restoration measures were also given. The results of the work are shown in Table 2.

As outlined in Table 2, the cost of the preemptive work is around one-third of that of traditional replacement under normal working conditions. Additionally, emergency replacement could further increase the cost of the work.

Table 2 Actual and estimated costs for assessment and restoration work and guarantee, compared to cost of full replacement.

\begin{tabular}{ll}
\hline Item & Cost \\
\hline Basic condition assessment: 3,831 feet at $\$ 18(15 \%$ of $\$ 120)$ & $\$ 68,958$ \\
Report including asset management and prescription for restoration with performance guarantee: & $\$ 22,986$ \\
3,831 feet at $\$ 6(5 \%$ of $\$ 120)$ & $\$ 20,000$ \\
Year 1 prescription: 10 clamps installed at $\$ 2,000$ & $\$ 16,500$ \\
Year 1 prescription: 5 segments replaced at $\$ 3,300$ & $\$ 10,850$ \\
Year 1 prescription: 31 anodes installed at $\$ 350$ & $\$ 7,780$ \\
Year 5 prescription: 26 anodes installed at350, present value, discounting at 4\% & $\$ 147,074$ \\
Total cost of assessment, restoration and guarantee & $\$ 459,720$ \\
Cost of full replacement: 3,831 feet at $\$ 120$ & \\
\hline
\end{tabular}


Table 3 Summary of unit costs from case studies.

\begin{tabular}{lll}
\hline Utility & Technology & Unit cost $(\$ / L F)$ \\
\hline \multirow{2}{*}{ SWBNO } & SmartBall & 3.73 \\
& LeakFinder & 2.93 \\
\hline AWWU & SmartBall & 10.83 (includes consulting on CA work) \\
\hline \multirow{2}{*}{ WSSC } & SmartBall & 28.00 \\
& CCTV & 15.15 \\
SPU (Seattle Public & Acoustic & 26.70 (per year) \\
Utilities) & Hydroscope & 18.00 \\
\hline
\end{tabular}

\section{Pipeline Management Project Cost Map}

Show: $\nabla$ CCTV $\square$ Zoom Cam $\square$ Sonar $\square$ Electro-scanning $\square$ Remote field testing

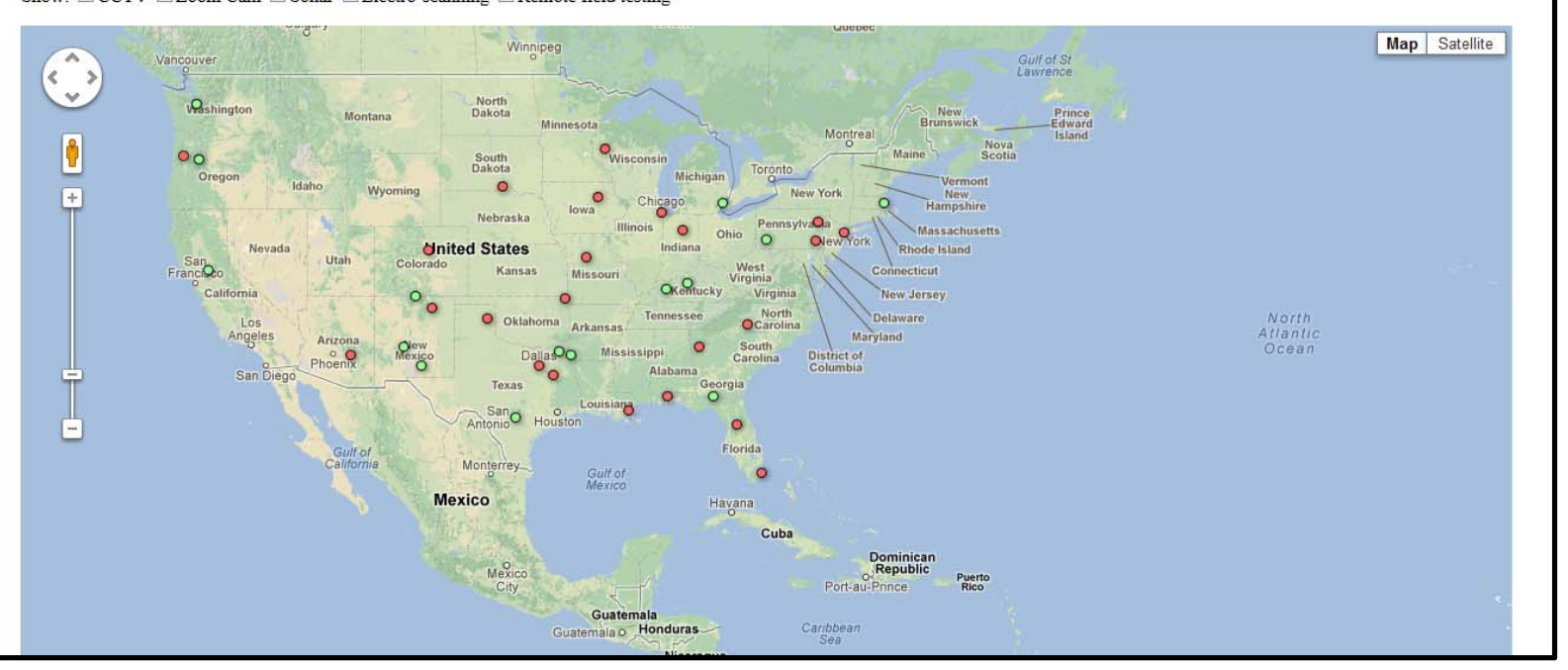

Fig. 3 Interactive web map for cost trending.

Table 3 contains a unit cost summary of the case studies described above.

\section{Interactive Cost Information Web Map}

Cost data gathered from the utilities were then used to create a shape file to enter it into a geographic information system. Google Maps API (application program interface) for JavaScript was then used to create in interactive web map designed to allow the user to search for geographic trends in a simple and useful manner. Users were given the option to toggle the data based on type and the instances of a certain type of project are then instantiated on the map. The projects appear as points and the size of the point varies based on the unit cost. The user can then click on a city of interest and the completed version of Table 1 for the specific project is rendered. This map is shown in
Fig. 3 where the user has selected CCTV (closed circuit television) camera inspection and electro-scanning as the types of projects to query. The CCTV projects appear in red and the electro-scan projects in green.

\section{Conclusions and Future Work}

Cost data for condition assessment projects lie in many disparate forms and locations, or go unrecorded altogether. This paper summarized the condition assessment for drinking water pipelines cost information segment of the WATERiD project, aimed at developing a novel methodology and data standard for capturing the true cost of these projects in a uniform way. This pilot project developed standards in data keeping and management to capture the true costs related to condition assessment and projects for 
drinking water pipelines. These standards will enable drinking water utilities to analyze the cost data efficiently and define robust decision support. As a pilot, it was meant to inspire confidence in drinking water utilities that collecting and reporting in this manner will enable robust cost trend and driver statistical analyses of an unmatched solidarity. As this method is adopted across the country, it will provide utilities with the ability to determine and further optimize the value of in-place piping materials and minimize the costs from construction time and service disruptions. This paper outlined the experience had in research and practice reviews, including the implementation of the data collection methodology and standardization for capturing true cost data for condition assessment and projects in drinking water piping asset management. The results were then shown and explained in detail with support from case studies developed in the research process. Furthermore, it provided a discussion on the benefits of collecting cost data in this manner and the future of the work.

\section{References}

[1] ASCE (American Society of Civil Engineers). 2013. “2013 Report Card for America's Infrastructure." ASCE. Accessed May 5, 2013. http://www.infrastructure reportcard.org/drinking-water/.

[2] USEPA (US Environmental Protection Agency). 2008. "Understanding the Safe Drinking Water Act: US
Environmental Protection Agency." USEPA. Accessed April 12, 2013. http://www.epa.gov/safewater/sdwa/ pdfs/fs_30ann_sdwa_web.pdf.

[3] USEPA. 2010. State of Technology for Rehabilitation of Wastwater Collection Systems, (Contract No. EP-C-05-057, Task Order No. 58). USEPA.

[4] USEPA. 2009. "Asset Management: A Best Practices Guide, EPA 816-F-08-014.” USEPA. Accessed May 19, 2013. www.epa.gov/safe water.

[5] Allouche, E. N., and Freure, P. 2002. "Condition Assessment and Management of Municipal Sewers in Canada: State-of-the-Practice." Presented at the Annual Conference of the Canadian Society for Civil Engineering, Montréal.

[6] Clark, R., Sivaganesan, M., Selvakumar, A., and Sethi, V. 2002. "Cost Models for Water Supply Distribution Systems." Journal of Water Resources Planning and Management 128 (5): 312-21.

[7] Selvakumar, A., Clark, R., and Sivaganesan, M. 2002. "Cost for Water Supply Distribution System Rehabilitation." Journal of Water Resources Planning and Management 128 (4): 303-6.

[8] Yang, M., and Su, T. 2007. "An Optimization Model of Sewage Rehabilitation." Journal of Chinese Institute of Chemical Engineers 30 (4): 651-9.

[9] Matthews, J., and Allouche, E. 2009. "TTWorld: A Web-Portal for Assessing the Suitability of Trenchless Construction Methods for Utility Projects and Associated Social Cost Savings." Presented at ASCE Pipelines Specialty Conference, San Diego.

[10] Matthews, J., and Allouche, E. 2010. "A Social Cost Calculator for Utility Construction Projects." Presented at No Dig Conference, Chicago. Accessed March 22, 2013. http://www.nastt-nw.com/wp-content/uploads/2009/10/nd 10-conf-preview-1_final.pdf. 